\begin{tabular}{ll|l} 
Case Reports in & \multicolumn{2}{c}{ Case Rep Gastroenterol 2013;7:240-244 } \\
\cline { 2 - 3 } Gastroenterology & $\begin{array}{l}\text { DOI: 10.1159/000351877 } \\
\text { Published online: IVay 25, 2013 }\end{array}$ & $\begin{array}{l}\text { ○ 2013 S. Karger AG, Basel } \\
1662-0631 / 13 / 0072-0240 \$ 38.00 / 0 \\
\text { www.karger.com/crg }\end{array}$ \\
\hline & $\begin{array}{l}\text { This is an Open Access article licensed under the terms of the Creative Commons Attribution- } \\
\text { NonCommercial-NoDerivs 3.0 License (www.karger.com/OA-license), applicable to the } \\
\text { online version of the article only. Distribution for non-commercial purposes only. }\end{array}$
\end{tabular}

\title{
Acute Liver Failure Associated with Propylthiouracil in a Pregnant 26-Year-Old Woman
}

\author{
Tatsuo Miyamura Tatsuo Kanda Shoko Minemura Masato Nakamura \\ Shingo Nakamoto Xia Jiang Shuang Wu Shin Yasui Makoto Arai \\ Osamu Yokosuka \\ Department of Gastroenterology and Nephrology, Chiba University, Graduate School of \\ Medicine, Chiba, Japan
}

\section{Key Words}

Acute liver failure $\cdot$ First trimester $\cdot$ Immune tolerance $\cdot$ Pregnancy $\cdot$ Propylthiouracil

\begin{abstract}
It seems appropriate to use propylthiouracil to treat maternal hyperthyroidism during the first trimester of pregnancy. We present the case of a 26-year-old woman with acute liver failure associated with propylthiouracil during the first trimester of pregnancy. She was successfully treated without liver transplantation. Attention should be paid to the possible occurrence of propylthiouracil-induced hepatotoxicity even during the first trimester of pregnancy.
\end{abstract}

\section{Introduction}

Based on a re-analysis of medical files reported to the US Food and Drug Administration (FDA) (1982-2008) for acute liver failure associated with propylthiouracil (PTU), it has been recommended that attention should be paid to the use of this drug [1]. Previous studies showed that the effect of PTU was significantly less than that of radioiodine treatment, and also that the effect of methimazole (MMI) was the same as that of radioiodine [2]. As the relative risk of MMI-induced choanal atresia and MMI causing a specific pattern of rare teratogenic effects after first-trimester exposure were reported, it has been considered appropriate to use PTU to treat maternal hyperthyroidism during the first trimester of pregnancy [3]. On the other hand, it has been reported that PTU can induce severe hepatotoxicity

Tatsuo Kanda, MD, PhD

Department of Gastroenterology and Nephrology

Chiba University, Graduate School of Medicine

1-8-1 Inohana, Chuo-ku, Chiba 260-8670 (Japan)

E-Mail kandat-cib@umin.ac.jp 
Miyamura et al.: Acute Liver Failure Associated with Propylthiouracil in a Pregnant 26-Year-Old Woman

[3-6]. We report a rare case of acute liver failure in the first trimester during pregnancy, in PTU treatment following MMI for hyperthyroidism.

\section{Case Report}

A 26-year-old Japanese woman was referred to Chiba University Hospital for the treatment of acute liver failure. Blood tests showed serum alanine aminotransferase (ALT) $399 \mathrm{IU} / \mathrm{l}$, aspartate aminotransferase (AST) $590 \mathrm{IU} / \mathrm{l}$, alkaline phosphatase $677 \mathrm{IU} / \mathrm{l}$, total bilirubin $15.9 \mathrm{mg} / \mathrm{dl}$ and prothrombin time international normalized ratio 1.78. She was diagnosed with hyperthyroidism (Graves' disease) at age 14, and she was treated with MMI 1 year before admission to our hospital. Five months before admission, she started taking PTU instead of MMI in consideration of her upcoming childbirth. Three months before admission (at 4 weeks gestation), mild liver dysfunction appeared (AST 76 IU/l, ALT 88 IU/l and total bilirubin $1.8 \mathrm{mg} / \mathrm{dl}$ ). At 8 weeks gestation, her liver function test had not improved (AST $72 \mathrm{IU} / \mathrm{l}$, ALT $104 \mathrm{IU} / \mathrm{l}$ and total bilirubin $1.6 \mathrm{mg} / \mathrm{dl}$ ). One week before admission (at 11 weeks gestation), she underwent surgery for miscarriage at the first clinic. Three days before admission, she had developed fatigue and jaundice and was referred to our hospital. The clinical data at admission to our hospital are shown in table 1. She had no drug hypersensitivities, liver diseases, blood transfusion or history of surgery other than the above. She did not drink alcohol and had no family history of liver disease. Physical examination revealed jaundice but no consciousness disturbance. Ultrasound examination and computed tomography showed a non-atrophic liver and no ascites. There were no positivities for any viral markers (table 1). A drug lymphocyte stimulation test for PTU was positive (stimulation index 234\%; 100\% for control) [7]. We diagnosed her as acute liver failure associated with PTU, without presenting hepatic encephalopathy. We started medical treatment such as glycyrrhizin, vitamin $\mathrm{K}$ and gabexate mesilate administration and made preparations for urgent liver transplantation [6,7]. She improved and was discharged 26 days after admission (fig. 1).

During her hospitalization, 20 days after admission, liver biopsy was performed (fig. 2), and the specimen showed preserved architecture of the liver, with centrilobular necrosis and ceroid granules also being observed, findings compatible with drug-related liver injury.

\section{Discussion}

In the present case, the total dose of PTU was $5,700 \mathrm{mg}$, but until the onset of liver dysfunction, the dose of PTU was 1,400 mg. Unlike MMI, the side effects of PTU are not doserelated [6]. We diagnosed her as acute liver failure associated with PTU, as other causes could be ruled out. PTU-induced hepatotoxicity is rare but potentially lethal, with a spectrum of liver injury ranging from asymptomatic elevation of ALT levels to acute liver failure and death [6, 8-13]. Over the past 60 years of PTU and MMI use, reports of PTU-related liver failure and death have accumulated [13].

The FDA reported that of 32 patients taking PTU who developed serious liver injury, 13 died and 11 required a liver transplant, and that of 5 adults taking MMI who developed serious liver injury, 3 died [14]. A multicenter study from Korea reported that the risk of hepatic adverse drug events evaluated by the reported odds ratio values was high with PTU [15]. Current PTU use in children should be stopped in favor of alternate therapies [16]. PTU may be the treatment of choice during, and just before, the first trimester of pregnancy [5] 
Miyamura et al.: Acute Liver Failure Associated with Propylthiouracil in a Pregnant 26-Year-Old Woman

because it is believed that MMI has a relative risk of choanal atresia in the first trimester of pregnancy [3].

Sequeira et al. [6] reported a case with severe PTU-induced hepatotoxicity in the second trimester of pregnancy. Acute liver failure during pregnancy occurs more frequently in the third trimester of gestation, and its etiology is usually related to acute fatty liver of pregnancy and infectious diseases $[17,18]$. Of interest in our case was the fact that severe PTUassociated acute liver failure occurred in the first trimester.

In the present case, the patient's liver function transiently worsened after surgery due to miscarriage. Pregnancy induces a state of immune tolerance with improvement of liver tests, and a flare-up often occurs after delivery as in autoimmune hepatitis [19]. It is possible that an immune mechanism of hepatotoxicity is involved in PTU-associated liver injury. In conclusion, clinicians should pay attention to the possible occurrence of PTU-induced hepatotoxicity even during the first trimester of pregnancy.

\section{Acknowledgement}

The authors thank all medical staff at the liver unit of Chiba University School of Medicine Hospital.

\section{Disclosure Statement}

Dr. Tatsuo Kanda reports receiving lecture fees from Chugai Pharmaceutical, MSD, Ajinomoto and GlaxoSmithKline, and Prof. Osamu Yokosuka reports receiving grant support from Chugai Pharmaceutical, Bayer, MSD, Daiichi-Sankyo, Mitsubishi Tanabe Pharma and Bristol-Myers Squibb.

\section{References}

1 Glinoer D, Cooper DS: The propylthiouracil dilemma. Curr Opin Endocrinol Diabetes Obes 2012;19: 402-407.

2 Copper DS: Antithyroid drugs in the management of patients with Graves' disease: an evidence-based approach to therapeutic controversies. J Clin Endocrinol Metab 2003;88:3474-3481.

-3 Hackmon R, Blichowski M, Koren G: The safety of methimazole and propylthiouracil in pregnancy: a systemic review. J Obstet Gynaecol Can 2012;34:1077-1086.

4 Morris CV, Goldstein RM, Cofer JB, Solomon H, Klintmalm GB: An unusual presentation of fulminant hepatic failure secondary to propylthiouracil therapy. Clin Transpl 1989:311.

-5 Karras S, Tzotzas T, Krassas GE: Toxicological considerations for antithyroid drugs in children. Expert Opin Drug Metab Toxicol 2011;7:399-410.

-6 Sequeira E, Wanyonyi S, Dodia R: Severe propylthiouracil-induced hepatotoxicity in pregnancy managed successfully by liver transplantation: a case report. J Med Case Rep 2011;5:461.

-7 Kanda T, Yokosuka O, Fujiwara K, Saisho H, Shiga H, Oda S, Okuda K, Sugawara Y, Makuuchi M, Hirasawa H: Fulminant hepatic failure associated with triazolam. Dig Dis Sci 2002;47:1111-1114.

-8 Carrion AF, Czul F, Arosemena LR, Selvaggi G, Garcia MT, Tekin A, Tzakis AG, Martin P, Ghanta RK: Propylthiouracil-induced acute liver failure: role of liver transplantation. Int J Endocrinol 2010;2010: 910636.

-9 Livadas S, Xyrafis X, Economou F, Boutzios G, Christou M, Zerva A, Karachalios A, Palioura H, Palimeri S, Diamanti-Kandarakis E: Liver failure due to antithyroid drugs: report of a case and literature review. Endocrine 2010;38:24-28.

10 Malozowski S, Chiesa A: Propylthiouracil-induced hepatotoxicity and death. Hopefully, never more. J Clin Endocrinol Metab 2010;95:3161-3163.

11 Primeggia J, Lewis JH: Gone (from the physicians' desk reference) but not forgotten: propylthiouracilassociated hepatic failure: a call for liver test monitoring. J Natl Med Assoc 2010;102:531-534. 
Miyamura et al.: Acute Liver Failure Associated with Propylthiouracil in a Pregnant 26-Year-Old Woman

12 Sipe WEB, Su M, Posselt A, Kim GE, Quiros JA, Rosenthal P: Propylthiouracil-associated liver failure presenting as probable autoimmune hepatitis in a child with Graves' disease. Pediatr Transplant 2006;10: 525-528.

13 Rivkees SA, Mattison DR: Ending propylthiouracil-induced liver failure in children. N Engl J Med 2009;360: 1574-1575.

14 Kuehn BM: FDA focuses on drugs and liver damage: labeling and other changes for acetaminophen. JAMA 2009;302:369-371.

-15 Kwon H, Lee SH, Kim SE, Lee JH, Jee YK, Kang HR, Park BJ, Park JW, Hong CS: Spontaneously reported hepatic adverse drug events in Korea: multicenter study. J Korean Med Sci 2012;27:268-273.

16 Rivekees SA, Mattison DR: Propylthiouracil (PTU) hepatotoxicity in children and recommendations for discontinuation of use. Int J Pediatr Endocrinol 2009;2009:132041.

17 Goel A, Nair SC, Viswabandya A, Masilamani VP, Rao SV, George A, Regi A, Jose R, Zachariah U, Subramani K, Eapen CE, Chandy G: Preliminary experience with use of recombinant activated factor VII to control postpartum hemorrhage in acute fatty liver of pregnancy and other pregnancy-related liver disorders. Indian J Gastroenterol 2013, Epub ahead of print.

18 Toti L, Manzia TM, Romano P, Lenci I, Baiocchi L, Anselmo A, Sforza D, Manuelli M, Tisone G: Successful management of a same-day emergency delivery and liver transplant in a 27 weeks pregnant woman with fulminant hepatic failure. Transplant Int 2010;23:114-115.

19 Buchel E, Van Steenbergen W, Nevens F, Fevery J: Improvement of autoimmune hepatitis during pregnancy followed by flare-up after delivery. Am J Gastroenterol 2002;97:3160-3165.

Table 1. Laboratory data on admission to Chiba University Hospital

\begin{tabular}{llll}
\hline White blood cells & $6,700 / \mu \mathrm{l}$ & HBsAg & - \\
Eosinophils & $7.1 \%$ & IgM-HBc & - \\
Red blood cells & $493 \times 10^{4} / \mu \mathrm{l}$ & HBV DNA & - \\
Hemoglobin & $11.0 \mathrm{~g} / \mathrm{dl}$ & IgM-HA & - \\
Platelets & $23.7 \times 10^{4} / \mu \mathrm{l}$ & Anti-HCV & - \\
PT\% & $29 \%$ & HCV RNA & - \\
PT-INR & 1.78 & HEV RNA & $1,456 \mathrm{mg} / \mathrm{dl}$ \\
Total cholesterol & $163 \mathrm{mg} / \mathrm{dl}$ & IgG & $294 \mathrm{mg} / \mathrm{dl}$ \\
Total protein & $6.0 \mathrm{~g} / \mathrm{dl}$ & IgA & $176 \mathrm{mg} / \mathrm{dl}$ \\
Albumin & $3.1 \mathrm{~g} / \mathrm{dl}$ & IgM & $0.60 \mathrm{ng} / \mathrm{ml}$ \\
AST & $590 \mathrm{IU} / \mathrm{l}$ & HGF & - \\
ALT & $399 \mathrm{IU} / \mathrm{l}$ & IgM-EBV VCA & - \\
LDH & $213 \mathrm{IU} / \mathrm{l}$ & IgM-CMV & - \\
$\gamma$-GTP & $68 \mathrm{IU} / \mathrm{l}$ & IgM-HSV & - \\
ALP & $677 \mathrm{IU} / \mathrm{l}$ & Anti-HIV & - \\
Total bilirubin & $15.9 \mathrm{mg} / \mathrm{dl}$ & Antinuclear antibody & - \\
Ammonia & $107 \mu \mathrm{dl}$ & ASMA & - \\
TSH & $0.01 \mu \mathrm{IU} / \mathrm{ml}$ & AMA & $26 \mathrm{mg} / \mathrm{dl}$ \\
Free T3 & $2.28 \mathrm{pg} / \mathrm{ml}$ & Ceruloplasmin & $35.3 \mathrm{ng} / \mathrm{ml}$ \\
Free T4 & $0.87 \mathrm{ng} / \mathrm{ml}$ & AFP & \\
\hline
\end{tabular}

AFP = Alpha-fetoprotein; ALP = alkaline phosphatase; ALT = alanine aminotransferase; AMA = anti-mitochondrial antibody; anti-HCV = HCV antibody; ASMA = anti-smooth muscle antibody; $\mathrm{AST}=$ aspartate aminotransferase; $\mathrm{LDH}=$ lactate dehydrogenase; free $\mathrm{T} 3$ = free triiodothyronine; free T4 = free thyroxine; $\gamma$-GTP = gamma-glutamyl transpeptidase; HBsAg = hepatitis B (HB) surface antigen; $\mathrm{HGF}=$ hepatocyte growth factor; $\operatorname{IgA}=$ immunoglobulin $\mathrm{A}$; $\operatorname{IgG}=$ immunoglobulin $\mathrm{G}$; IgM = immunoglobulin M; IgM-HA = hepatitis A antibody IgM; IgM-HBc = HB core IgM antibody; PT-INR = prothrombin time international normalized ratio; TSH = thyroid-stimulating hormone; $-=$ negative. 
Miyamura et al:: Acute Liver Failure Associated with Propylthiouracil in a Pregnant 26-Year-Old Woman

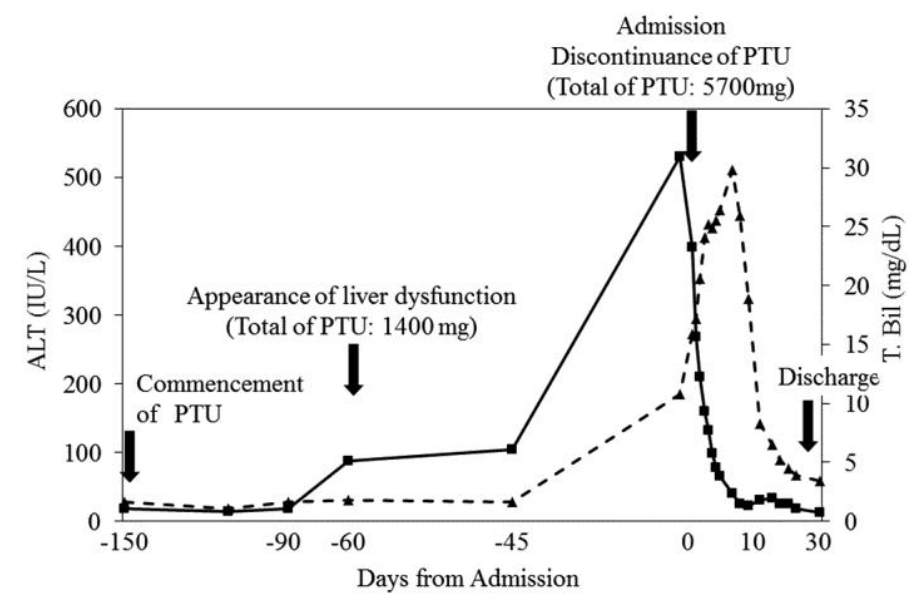

Fig. 1. Chart describing the course of ALT (black squares) and total bilirubin (black triangles) from the commencement of PTU administration until 1 week after discharge. ALT levels peaked at 531 IU/l. The total dose of PTU was 5,700 mg before admission. The patient improved after stopping PTU.

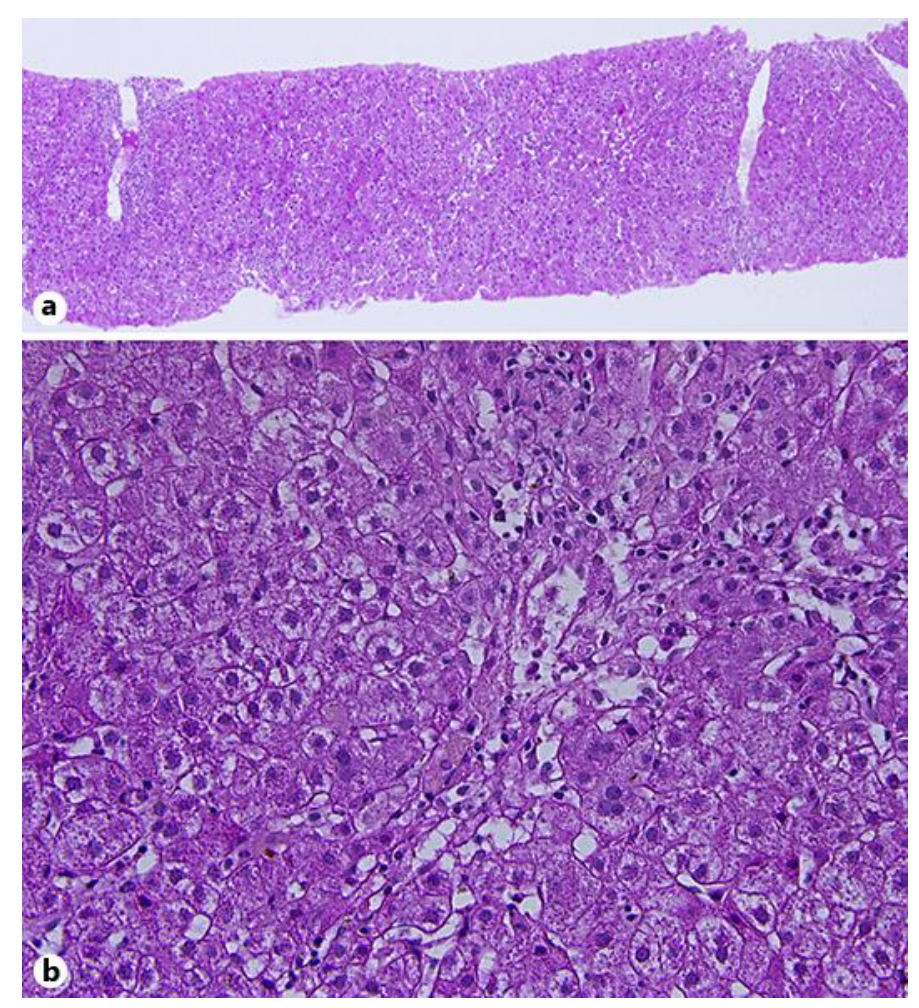

Fig. 2. Liver biopsy showed normal architecture of the liver and no cirrhosis (hematoxylin and eosin; original magnification 40x) (a). Centrilobular necrosis was also found (hematoxylin and eosin; original magnification $200 \times$ ) (b). We diagnosed the patient as drug-induced liver injury associated with PTU. 